Ч. П. Федорова. Модель управления качеством производственной практики через организацию сетевого взаимодействия

Научная статья

УДК 378.147 .88

DOI: $10.18101 / 2307-3330-2021-1-51-58$

\title{
МОДЕЛЬ УПРАВЛЕНИЯ КАЧЕСТВОМ ПРОИЗВОДСТВЕННОЙ ПРАКТИКИ ЧЕРЕЗ ОРГАНИЗАЦИЮ СЕТЕВОГО ВЗАИМОДЕЙСТВИЯ
}

\author{
(C) Федорова Чимита Петровна \\ преподаватель педагогики, \\ Боханский педагогический колледж им. Д. Банзарова \\ 669311, Россия, п. Бохан, Иркутская обл. ул. Набережная 27 \\ chimita907@mail.ru
}

\begin{abstract}
Аннотация. В статье описывается модель управления качеством производственной практики студентов педагогического колледжа через организацию сетевого взаимодействия. Автор указывает на актуальность разработки и реализации модели, описывает основные идеи и требования к разрабатываемой модели. В статье раскрываются этапы моделирования процесса управления качеством производственной практики через организацию сетевого взаимодействия педагогического колледжа и организаций - баз практики. Представлена структура сконструированной модели, включающая субъекты сетевого взаимодействия, управляющую и управляемую системы, функции и содержание компонентов модели управления, критерии оценки результативности модели управления. Особое внимание уделено взаимодействию управляющей и управляемой систем как цепи взаимосвязанных, последовательных управленческих действий, включающих целевой, содержательный, процессуальный, оценочнорезультативный компоненты.
\end{abstract}

Ключевые слова: модель управления, производственная практика, компоненты модели, субъекты сетевого взаимодействия, управляющая и управляемая система

\section{Для цитирования}

Федорова Ч. П. Модель управления качеством производственной практики через организацию сетевого взаимодействия // Вестник Бурятского государственного университета. Образование. Личность. Общество. 2021. Вып. 1. С. 51-58.

Изучая проблему управления качеством производственной практики в среднем профессиональном образовании в рамках организации сетевого взаимодействия профессиональной образовательной организации с организациями - базами практики, мы пришли к выводу о необходимости совершенствования данного процесса путем предварительного создания некоего образа - модели. Модель будет выступать ориентиром для всех субъектов сетевого взаимодействия: представителей профессиональной образовательной организации (обучающиеся, преподаватели, руководители производственной практики, администрация) и организаций - баз производственной практики (руководители-работодатели, педагоги-наставники).

Разработка и реализация модели позволит предвидеть цель и задачи, подбирать необходимые методы, средства и формы организации производственной практики будущих учителей начальных классов, выявить критерии и показатели 
оценки качества реализации производственной практики в рамках сетевого взаимодействия.

Как метод педагогического исследования моделирование широко используется в педагогической науке, наряду с наблюдением и экспериментом. Научное обоснование данного метода представлено в исследованиях ученых, таких как Н. В. Бордовская, А. Н. Дахин, В. И. Загвязинский, А. М. Новиков, А. А. Реан, А. С. Сиденко и др.

Модель - стандарт, образец, аналог. Модель применяется в том случае, когда необходимо что-то представить в наглядном формате, с целью изучения исследуемого явления [3].

Мы в своем исследовании рассматриваем модель как систему, мысленно представляемую и материально реализованную, которая отображает и воспроизводит объект исследования, замещает его и дает возможность его изучить с целью получения новой информации. Разрабатываемая нами модель управления качеством производственной практики через организацию сетевого взаимодействия является структурно-функциональной, будет содержать внутреннюю и внешнюю сторону организации процесса управления и отображать взаимосвязь элементов модели.

Основные требования к разрабатываемой нами модели следующие:

- результатом функционирования модели должно стать повышение качества производственной практики;

- она должна учитывать основные требования, которые предъявляет работодатель к будущему высококвалифицированному специалисту, к его профессиональным и личностным качествам;

- при построении модели следует учитывать интересы как профессиональной образовательной организации, так и организаций - баз практики;

- модель должна носить опережающий характер, то есть предвидеть долгосрочные перспективы в подготовке специалиста;

- производственная практика, реализуемая в ходе сетевого взаимодействия, должна максимально точно моделировать практическую деятельность будущего учителя;

- модель должна быть динамичной, то есть способной подстраиваться под изменяющиеся требования общества и работодателя;

- модель должна отражать формируемый практический опыт деятельности, полученный в ходе производственной практики, с помощью которых мы сможем оценить качество производственной практики в целом.

Моделирование процесса управления качеством производственной практики через организацию сетевого взаимодействия педагогического колледжа и организаций — баз практики предполагает несколько этапов:

- обобщение успешного опыта управления качеством сетевого взаимодействия профессиональных образовательных организаций и организаций - баз практики, его анализ и формулировка на его основе гипотезы исследования; 
Ч. П. Федорова. Модель управления качеством производственной практики через организацию сетевого взаимодействия

- составление программы исследования, организация сетевого взаимодействия в соответствии с разработанной программой, внесение корректировок в процесс на основе практической производственной деятельности;

- создание и утверждение окончательного варианта модели, реализация ее на практике.

Объективными предпосылками для построения модели управления качеством производственной практики через организацию сетевого взаимодействия являются:

- наличие работодателей, заинтересованных в реализации производственной практики на базе своих организаций;

- наличие учреждения среднего профессионального образования, способного выполнить заказ организаций - баз практики;

- наличие у профессиональной образовательной организации социальных партнеров;

- возможность проведения всех видов практик в организациях - субъектах сетевого взаимодействия;

- возможность прохождения стажировок преподавателей, руководителей практики в организациях — базах практики;

- участие представителей организаций - баз практики в оценке качества общих и профессиональных компетенций по итогам производственной практики;

- возможность использования материально-технической базы всех участников сетевого взаимодействия;

- возможность отбора лучших обучающихся для заключения трудовых договоров;

- возможность организаций - баз практики влиять на содержание образования и организацию учебного процесса в профессиональной образовательной организации.

Данные предпосылки стали основой формулирования цели реализации модели - повышение качества производственной практики студентов профессиональной образовательной организации через организацию сетевого взаимодействия.

Разработанная нами структурно-функциональная модель управления качеством производственной практики через организацию сетевого взаимодействия представлена на рисунке 1.

Основная идея сконструированной модели заключается в изменении характера взаимодействия субъектов управления качеством производственной практики посредством различных форм, методов, механизмов управления. Интеграция ресурсов субъектов сетевого взаимодействия (интеллектуальных, материальных, технических) является системообразующим фактором для повышения качества производственной практики, в процессе которой формируются необходимые профессиональные компетенции [4, с. 56]. 


\begin{tabular}{|c|c|c|c|c|c|}
\hline \multicolumn{6}{|c|}{ Субъекты сетевого взаимодействия } \\
\hline \multicolumn{2}{|c|}{$\begin{array}{c}\text { Учреждение } \\
\text { СПО }\end{array}$} & $\begin{array}{c}\text { Образовательные } \\
\text { организации }\end{array}$ & $\begin{array}{c}\text { Учреждения ДО } \\
\text { (ДШИ, ДДТ ) }\end{array}$ & \multicolumn{2}{|l|}{$\begin{array}{c}\text { Детские оздоровит. } \\
\text { лагеря }\end{array}$} \\
\hline & & $\mathbf{4}$ & Система управ. & ения & \\
\hline \multicolumn{2}{|c|}{$\begin{array}{c}\text { Компоненты, } \\
\text { функции }\end{array}$} & \multicolumn{2}{|c|}{ Управляющая система } & \multicolumn{2}{|c|}{ Управляемая система } \\
\hline 罟 & 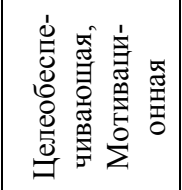 & $\begin{array}{r}\text { Проведен } \\
\text { прс } \\
\text { Заключен } \\
\text { Оценка МТ }\end{array}$ & $\begin{array}{l}\text { экспертизы } \\
\text { рамм. } \\
\text { е договоров. } \\
\text { организаций }\end{array}$ & $\begin{array}{r}\text { Заказ необх } \\
\text { Эксперти } \\
\text { Определен }\end{array}$ & $\begin{array}{l}\text { димых кадров. } \\
\text { за программ. } \\
\text { Iе наставников }\end{array}$ \\
\hline \\
\hline 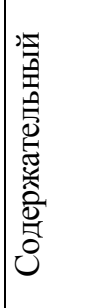 & 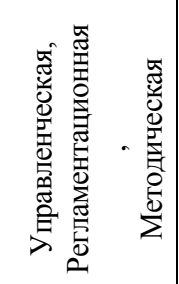 & \multicolumn{2}{|c|}{$\begin{array}{c}\text { Планирование работы центра. } \\
\text { Разработка, согласование про- } \\
\text { грамм ПП, КОС, методических } \\
\text { рекомендаций, курсов повыше- } \\
\text { ния квалификации, } \\
\text { наставничества }\end{array}$} & \multicolumn{2}{|c|}{$\begin{array}{c}\text { Согласование программ. } \\
\text { Разработка УМО практики, про- } \\
\text { граммы стажировки, } \\
\text { наставничества }\end{array}$} \\
\hline 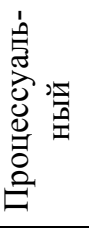 & 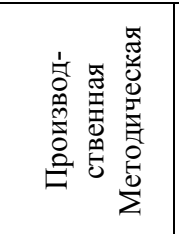 & \multicolumn{2}{|c|}{$\begin{array}{c}\text { Организация, контроль ПП. } \\
\text { Стажировка преподавателей. } \\
\text { Проведение курсов ПК. } \\
\text { Реализация программы центра } \\
\text { Реализация программы } \\
\text { наставничества }\end{array}$} & \multicolumn{2}{|c|}{$\begin{array}{c}\text { ПП под руководством наставников. } \\
\text { Проведение стажировок. } \\
\text { Реализация программы } \\
\text { наставничества }\end{array}$} \\
\hline \multirow[t]{3}{*}{ 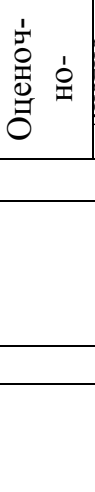 } & 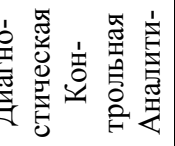 & \multicolumn{2}{|c|}{$\begin{array}{c}\text { Диагностика ОК, ПК } \\
\text { Оценка показателей эффективно- } \\
\text { сти модели управления }\end{array}$} & \multicolumn{2}{|c|}{$\mapsto \begin{array}{c}\text { Оценка ОК, ПК практикантов. } \\
\text { Оценка показателей эффективности } \\
\text { модели управления }\end{array}$} \\
\hline & \multicolumn{5}{|c|}{$\begin{array}{c}\text { Критерии оценки: } \\
\text { качество производственной практики - уровни сформированности ОК и ПК } \\
\text { эффективность организации ПП - кадровое, методическое, материально- } \\
\text { техническое обеспечение, человеческий фактор } \\
\end{array}$} \\
\hline & & $\begin{array}{r}\text { оценка эффект } \\
\text { через ор }\end{array}$ & $\begin{array}{r}\text { Результат: } \\
\text { сти модели упр } \\
\text { ззацию сетевого }\end{array}$ & $\begin{array}{l}\text { вления качеством П } \\
\text { заимодействия }\end{array}$ & \\
\hline
\end{tabular}

Pис. 1 
Ч. П. Федорова. Модель управления качеством производственной практики через организацию сетевого взаимодействия

В структуру модели управления качеством производственной практики через организацию сетевого взаимодействия входят два взаимосвязанных и взаимозависимых блока: управляющая система и управляемая система. Взаимодействие и взаимовлияние управляющей и управляемой систем это цепь взаимосвязанных, последовательных управленческих действий, а модель представляет собой завершенную оформленную структуру.

Модель содержит следующие компоненты: целевой, содержательный, процессуальный, оценочно-результативный.

Целевой компонент реализует следующие функции:

целеобеспечивающая - формулировка цели реализации модели управления и основных стратегических задач по ее достижению, определение организационнопедагогических условий управления, позволяющих повысить качество производственной практики через организацию сетевого взаимодействия;

мотивачионная - формирование положительной мотивации к реализации модели управления качеством производственной практики через организацию сетевого взаимодействия у всех заинтересованных субъектов данного процесса, раскрытие основных перспектив, преимуществ ее реализации.

На данном этапе выясняются возможности организаций - баз практики в создании необходимых условий для организации производственной практики и заключаются договоры с педагогическим колледжем. Педагогический коллектив совместно с ведущими специалистами организаций - баз практики разрабатывают требования, предъявляемые к практиканту в процессе производственной практики, определяют критерии и показатели, по которым будет возможно судить о качестве подготовки студентов, выделяют и описывают уровни подготовки: низкий, пороговый, средний, высокий.

Следующим шагом в реализации модели является подготовка педагогов, руководителей практики от колледжа, наставников со стороны организаций - баз практики. Для этого проводятся экскурсии на базы практики, педагоги и руководители практики знакомятся с материально-технической базой организации, условиями осуществления производственной практики.

Для наставников со стороны организаций - баз практики в колледже проводятся семинары с целью знакомства с педагогическими технологиями, методами психолого-педагогического сопровождения процесса прохождения студентами производственной практики в организации. Ведущие специалисты организацийбаз практики, представители руководства осуществляют содержательную экспертизу специальных дисциплин и профессиональных модулей, согласовывают рабочие программы учебной и производственной практики. Составляется календарный учебный план, при этом в первую очередь учитываются интересы организаций - баз практики, так как реализация производственной практики не должна снижать эффективность учебно-воспитательного процесса.

Следующим шагом реализации целевого компонента является работа с практикантами, совместно с представителями организаций - баз практики, производится диагностика уровня их подготовленности, с каждым практикантом проводится индивидуальное собеседование. В дальнейшем студентов знакомят с условиями 
работы в организации, проводят экскурсии, рассказывают о перспективах работы, тем самым обеспечивая мотивационно-личностное наполнение процесса сетевого взаимодействия колледжа и организаций — баз практики.

Функциями содержательного компонента модели выступают:

организационно-управленческая - принятие управленческих решений, касающихся организации сетевого взаимодействия и производственной практики;

регламентационная - распределение ролей всех субъектов сетевого взаимодействия (студенты, наставники, руководители практики, руководство организаций баз практики), определение требований к ним, а также их возможностей, прав и обязанностей;

методическая - разработка необходимой методической документации для реализации производственной практики.

Содержательный компонент предполагает содержательное наполнение процесса производственной практики. За студентами-практикантами закрепляются руководители со стороны колледжа и наставники из числа ведущих специалистов организаций - баз практики. Определяются классы, группы в организациях - базах практики, где будет проходить практика, составляются графики стажировки в соответствии с наличием учебных мест.

Руководители организаций - баз практики заполняют гарантийные письма о согласии определить студентов в данном классе, группе, отряде на время производственной практики. На основе гарантийных писем, договоров о сетевом взаимодействии заместитель директора по учебно-производственной работе педагогического колледжа готовит проект приказа о распределении студентов на производственную практику. После подготовки приказа студенты профессиональных образовательных организаций направляются на практику в организации - базы практики.

Содержательный компонент включает программы повышения квалификации педагогических работников.

Данный компонент содержит также организацию стажировок преподавателей специальных дисциплин, профессиональных модулей и руководителей практики, на которых педагогический состав профессиональной образовательной организации получает необходимый практический опыт работы на базе практики. Стажировка позволяет наладить взаимодействие между преподавателями и руководителями практики от колледжа, отвечающими в большей степени за теоретические знания, наставниками и сотрудниками организаций - баз практики, отвечающими за практическое производственное обучение, в рамках реализации сетевого взаимодействия.

Содержательный компонент включает организацию наставничества, закрепление за наставниками студентов для передачи педагогического опыта, проведение мероприятий, направленных на обобщение и распространение передового педагогического опыта.

Процессуальный компонент включает непосредственно производственную деятельность практикантов под руководством наставников, освоение студентами на рабочем месте последовательности технологических и производственных операций, обеспечивающих усвоение профессиональных компетенций, моделирование содержания профессиональной педагогической деятельности, условий труда. Роль 
Ч. П. Федорова. Модель управления качеством производственной практики через организацию сетевого взаимодействия

наставников заключается в непосредственном руководстве производственной деятельностью студентов, оказании помощи в адаптации к условиям учреждения. Студенты перенимают передовой педагогический опыт наставников, осознают динамичность и многозадачность учебно-воспитательного процесса. Осуществляется оценка качества производственной практики студентов со стороны наставников и руководства организации - базы практики. Руководители практики от профессиональной образовательной организации контролируют качество прохождения производственной практики в организациях - базах практики, обеспечивают студентов необходимыми теоретическими знаниями, следят за их посещаемостью и трудовой дисциплиной.

Оценочно-результативный блок предусматривает оценку и определение фактического уровня общих и профессиональных компетенций студентов, на формирование которого был направлен процесс производственной практики, а также оценку компонентов системы производственной практики. Качество производственной практики определяется в процессе оценки общих и профессиональных компетенций студентов по итогам производственной практики с участием представителей работодателя, а также в ходе специального диагностического исследования компонентов. Решение о присвоении того или иного уровня сформированности общих и профессиональных компетенций студентов основывается на экспертной оценке, в которой участвуют представители колледжа и организаций - баз практики.

Представители педагогического колледжа осуществляют мониторинг трудоустройства выпускников, поддерживают с ними контакт, выясняют эффективность их трудовой деятельности, так она является ведущим показателем успешности реализации модели сетевого взаимодействия.

В оценочно-результативном компоненте реализуются следующие функции:

диагностическая - оценка достижения запланированных целей и задач в рамках модели сетевого взаимодействия (оцениваются сформированные компетенции, компоненты подготовки и проведения производственной практики, необходимые для успешной производственной деятельности);

контрольная - сопоставление полученных результатов с критериями, распределение студентов по уровням;

аналитическая - обобщение, интерпретация полученных результатов, корректировка содержания компонентов модели управления, на основе полученных данных

Разработанная нами модель сетевого взаимодействия педагогического колледжа и организаций - баз практики имеет практико-ориентированный характер, представляет искомый процесс как педагогическую систему, состоящую из взаимосвязанных компонентов, результатом функционирования которой должно стать повышение качества производственной практики в педагогическом колледже.

Лumepamypa

1. Гиссин В. И. Управление качеством: учебное пособие. Москва: МарТ; Ростов-наДону: МарТ, 2018. 400 с. Текст: непосредственный.

2. Грушникова Е. В. Управление повышением квалификации педагогов в сетевом взаимодействии образовательных организаций: специальность 13.00.08 Теория и методика про- 
фессионального образования: диссертация на соискание ученой степени кандидата педагогических наук. Бийск, 2015. 223 с. Текст: непосредственный.

3. Захарова Г. Н. Модель управления качеством профессиональной подготовки студентов ОГОУ «ТГПК». URL: https://urok.1sept.ru/articles/531473 (дата обращения: 10.01.2021). Текст: электронный.

4. Лизунов П. В. Сетевое взаимодействие профессиональных образовательных организаций с предприятиями как фактор повышения качества подготовки студентов: специальность 13.00.08 Теория и методика профессионального образования: диссертация на соискание ученой степени кандидата педагогических наук; ФГБОУ ВО «Южно-Уральский государственный гуманитарно-педагогический университет», Челябинск, 2018. 211 с. Текст: непосредственный.

Статья поступила в редакичи 09.02.2021; одобрена после рещензирования 25.03.2021; принята к публикации 09.04.2021.

\title{
A MODEL FOR CONTROL OF THE QUALITY OF WORK EXPERIENCE INTERNSHIP THROUGH THE ORGANIZATION OF NETWORK INTERACTION
}

\author{
Chimita P. Fedorova \\ Teacher of Pedagogy, \\ Dorzhi Banzarov Bokhan Pedagogical College, \\ 27 Naberezhnaya St., Bokhan 669311, Russia \\ chimita907@mail.ru
}

Abstract. The article presents a model for quality control of work experience internship of pedagogical college students through the organization of network interaction. We emphasize the relevance of developing and implementing such a model, and describe the main ideas and requirements for it. The article reveals the stages of modeling the process of internship quality control through the organization of network interaction of the pedagogical college and practice bases. We have presented the structure of the constructed model: the subjects of network interaction, the controlling and controllable systems, the functions and content of the control model components, as well as the criteria for evaluating the effectiveness of the model. Special attention is paid to the interaction of the controlling and controllable systems as a chain of interrelated, consistent control actions, which include target, content, process, evaluation and performance components.

Keywords: a model for control; work experience internship; model components; subjects of network interaction; controlling and controllable systems.

For citation

Fedorova Ch. P. A Model for Control of the Quality of Work Experience Internship through the Organization of Network Interaction. Education. Person. Society. 2021; 1: 51-58 (In Russ.).

The article was submitted 09.02.2021; approved after reviewing 25.03.2021; accepted for publication 09.04.2021. 